\title{
Türkiye'de 81 İl İçin Bilgi Ekonomisi İndeksi Sıralamasının Oluşturulması: Çok Değişkenli Karar Verme Yöntemlerinden TOPSIS ile Bir Uygulama
}

\author{
Süha Çelikkaya ${ }^{1}$ \\ ORCID: 0000-0002-4104-1680
}

\author{
Vahap Karaçadır ${ }^{2}$ \\ ORCID: 0000-0002-0089-2112
}

\author{
Zeynep Ezanoğlu ${ }^{3}$ \\ ORCID: 0000-0002-4601-7567
}

Öz

Ülkelerin ekonomik gelişme düzeylerini belirleyen önemli faktörlerden biri olan bilginin, iktisadi gelişme seviyelerini giderek daha fazla etkilediği bilinmektedir. Bilgi ekonomisi yenilik, eğitim, bilgi ve iletişim teknolojileri yatırımların kapsamaktadır. Gelişmişlik seviyelerini arttırmak amacıyla, gelişmekte olan ve az gelişmiş ülkeler de bilgi ekonomisi olmaya yönelmişlerdir. Dünya genelinde bilgi teknolojilerinin yoğun olarak kullanılması ile birlikte bilgi ekonomisinde ileri olan ülkelerin yanı sıra kentlerinin de sosyal ve ekonomik gelişimini sağladığı bilinmektedir. Günümüzde bilgi ve iletişim teknolojilerinin gelişmesiyle birlikte yaşanan hızlı değişim, kent ekonomilerini gittikçe gǚclendirmiş ve kentler arasinda rekabetin belirleyici faktörlerinden olmuştur. Bu nedenle kentlerin rekabet gücünü artırmak için bilgi yoğun sistemleri geliştirmeye yoğunlaşması büyük önem taşımaktadır. Bu çalışmada; Türkiye'deki illerin belirli kriterler ile bilgi ekonomisi indeksi stralamasının oluşturulması amacıyla çok kriterli karar verme tekniklerinden birisi olan "TOPSIS" yöntemi kullanılmıştır. Yapılan sıralama sonuçlarına göre bilgi ekonomisi indeksi açısından ilk üç il sırasılyla: İstanbul, Ankara ve Manisa olarak bulunurken son sirada ise Ağrn ili yer almaktadır.

Anahtar Kelimeler: Bilgi ekonomisi, Kentler, TOPSIS Yöntemi.

\footnotetext{
${ }^{1}$ Dr. Öğr. Üyesi, Süleyman Demirel Üniversitesi, E-mail: suhacelikkaya@sdu.edu.tr

2 Doktora Öğrencisi, Süleyman Demirel Üniversitesi, E-mail: vahapkaracadir@hotmail.com

${ }^{3}$ Doktora Öğrencisi, Süleyman Demirel Üniversitesi, E-mail: zeynepezanoglu@gmail.com

idealkent (c) Kent Araştırmaları Dergisi (Journal of Urban Studies)

http://idealkentdergisi.com

Geliş Tarihi Received Date: 30.09.2020 Kabul Tarihi Accepted Date: 27.04.2021
} 


\title{
Creating Knowledge Economy Index Ranking for 81 Provinces in Turkey: An Application with TOPSIS, A Multivariate Decision Making Method
}

\author{
Süha Çelikkaya ${ }^{4}$ \\ ORCID: 0000-0002-4104-1680
}

\author{
Vahap Karaçadir ${ }^{5}$ \\ ORCID: 0000-0002-0089-2112
}

\author{
Zeynep Ezanoğlu ${ }^{6}$ \\ ORCID: 0000-0002-4601-7567
}

\begin{abstract}
Information is one of the important factors determining the economic development levels of countries and affecting the economic development growingly. Information economy covers investments in innovation, education, information and communication technologies. To increase their development level, developing and underdeveloped countries have focused on knowledge economies. Cities as well as countries that are advanced in information economy, provide social and economic development. Today, development of information and communication technologies has strengthened city economies and became one of the determining factors of competition. Therefore, it is of great importance for cities to concentrate on developing knowledge-intensive systems to increase their competitiveness. In this study, to obtain an index of knowledge economy in provinces of Turkey with certain criteria, a multi-criteria decision-making technique "TOPSIS" method is used. According to the results, the first three provinces in terms of information economy index are: Istanbul, Ankara and Manisa, while A $\breve{g r}$ is in the last row.
\end{abstract}

Keywords: Knowledge Economy, Cities, TOPSIS Method.

\footnotetext{
${ }^{4}$ Asts. Prof., Süleyman Demirel University, E-mail: suhacelikkaya@sdu.edu.tr ${ }^{5}$ PhD Student, Süleyman Demirel University, E-mail: vahapkaracadir@hotmail.com ${ }^{6}$ PhD Student, Süleyman Demirel University, E-mail: zeynepezanoglu@gmail.com idealkent @ C Kent Araştırmaları Dergisi (Journal of Urban Studies) http://idealkentdergisi.com

Geliş Tarihi Received Date: 30.09.2020 Kabul Tarihi Accepted Date: 27.04.2021
} 


\section{Giriş}

Geçmişte geleneksel üretim faktörlerine dayalı bir ekonomik kalkınma süreci bulunmaktayken 1980'lerden itibaren küreselleşme ve teknolojinin gelişmesi ile üretim yapısı giderek daha verimli hale gelerek ekonomik faaliyetlere yansımaktadır. Yeni mal ve hizmetlerin üretilmesi ve girişimcilik faaliyetlerinin artmasına yönelik gelişmeler ile beşerî sermayenin önemi gün geçtikçe artmaktadır (Dulupçu, 2001, s.45-53). Bu sebeple bilgiyi üretme ve kullanma yeteneği olarak adlandırılabilecek teknolojik yetenek, ekonomik büyümenin ve uluslararası rekabetin en önemli belirleyicilerinden birisi olmuştur. Teknolojik yetenek bakımından gelişmiş ülkeler iktisadi çalışmaların önemli kısmının bilgi yoğun faaliyetlerden oluştuğu bir süreç yaşamaktadır (Saygill, 2003, s.5). Bilginin üretimde faktör olarak kullanılmasıyla birlikte yeni çalışma alanları meydana gelmiştir. Sanayi yoğun sektörlerin temel aktörü olan sanayi işçisi, yerine bilgiyi kullanan bilgi işçisi geçmiştir (Oktay ve Kaynak, 2007, s.420). Temel teknolojilerde yaşanan ilerlemeyle beraber bilgi sektörünün, üretiminin, sermayesinin ve kalifiye insan faktörünün ön planda yer aldığı görülmektedir. Bu süreçte beşerî sermayenin kendini geliştirmesine bağlı olarak bilgi ağlarının, iletişim teknolojilerinin ve elektronik ticaret gibi alanların ilerlemesi sağlanmaktadır. Toplumun sosyal, siyasal ve kültürel olarak etkileyen sanayi toplumunun ötesine taşıyan bilgi toplumu meydana gelmiştir. Bilginin üretimi, kullanılması, yayılması, küresel ağlar üzerinde etkileşime girilmesi ile oluşan ekonomik değerler üzerine kurulu sisteme bilgi ekonomisi denilmektedir (Emiroğlu, 2007, s.35). Endüstri devrimi esnasında ortaya çıkan mali kaynak kullanımı artık yerini bilgi ekonomisine devretmiştir. Günümüz ekonomik koşullarının temel eksenini oluşturan bilgi ekonomisi, teknoloji kullanımı ile tüm dünya genelinde yaygınlaşarak ekonomik, sosyal ve kültürel kalkınmanın aracı haline gelmektedir (Kevük, 2006, s.320).

Toplumsal değişimler ekonomik faaliyetleri etkilediği gibi bilgiye dayalı ekonomik faaliyetler de gün geçtikçe artmaktadır. Bilgi etmeni, ilk olarak üretimde girdi olarak kullanılmakta daha sonra üretimde kullanılan bu bilgi miktarının artmasıyla birlikte malların katma değeri yükselmektedir. Bilgi temelli ekonomik faaliyetler ülkeleri giderek daha rekabetçi hale getirmektedir. Piyasalarda rekabet artarken mal ve hizmet kalitesi de yükselmektedir. (Ekizceleroğlu, 2011, s. 212). Bilgi ekonomisinin etkisi sadece teknoloji alanında değişimleri kapsamamaktadır. Aynı zamanda teknolojinin küresel boyuttaki yayılma hızını da artırmaktadır. İletişim teknolojileri sayesinde pek çok sektör ekono- 
milerdeki tüm gelişmeleri takip edebilmektedir. Bu durum, yeniliklerin küresel olarak yayılmasına ve çok sayıda fırsatla karşılaşılmasına yol açmaktadır (Coppel, 2000, s.19).

Bilgi ekonomisinin temel özelliklerine bakıldığında, bilginin önemli ve düşük maliyetli olması, internet sayesinde iletişim teknolojilerinin ilerlemesi ile yenilik takibinin kolaylaşması, kurumsal bağlamda kişiye ve insan sermayesine önem verilmesi ve ekonomik, politik ve kültürel konulara bağlı olarak güvenlik sorunları belirlenmesi bulunmaktadır (Yeloğlu, 2009, s.247). Ekonominin temel sermayesi olarak görülen bilgiyi kullanan kişi insandır. Bilgi, insanın belleğinde ve bilinçaltında tuttuğu yaratıcı yetisi ile sorun çözme aşamasında aktif olarak kullanmaktadır. Bu açıdan insan yalnızca işgücü, emek ya da personel olarak görülmemelidir. Bilginin kullanım şekline bakılarak bilgi ekonomisinde dört temel bileşen; küreselleşme, sayısallaşma, Ar-Ge çalışmaları ve insan kaynağında yaşanan köklü değişimdir (TÜSİAD, 2001). Bilgi ekonomisinin ölçümünde dinamik bir yenilik sistemi, eğitim, kurumsal ve ekonomik yapı ile yeterli bilgi sermayesi yer almaktadır (Chen ve Dahlman, 2005, s.4).

Bilgi ve iletişim teknolojilerinde yaşanan değişim, toplumların ekonomik, sosyal, siyasal ve kültürel olarak yeniden yapılanmasına neden olmuştur. Bu süreç sonucunda küresel ölçekte üretim ve mekanların yeniden şekillenmesinde kentlerin önemi büyük oranda artmıştır. Bilgi ekonomisinde yaşanan ilerlemeler ile birlikte çalışma kültürü ve ekonomik çeşitlilik yükselirken, kentler de önemli oranda gelişmiştir. Ayrıca bilgi ekonomisi gelişmekte olan ülkelerin kalkınmasında aktif bir rol üstlenmekte ve kentleri geliştirmektedir (Ataklı Yavuz, 2017, s. 266). Bu çalışmanın ana amacı, Türkiye'deki illeri bilgi ekonomisi indeksine göre sıralamaktır. Çalışmada Dünya Bankası tarafından geliştiren "Bilgi ekonomisi endeksi" kriterleri temel alınacaktır. Bu amaçla ideal Noktalarla Çok Boyutlu Ağırlıklandırma (TOPSIS [Technique for Order Preference by Similarity to Ideal Solution]) yöntemi kullanılmış ve bu yöntem için gerekli olan değişkenlerin ağırlıklarının belirlenmesinde Entropi Ağırlık yönteminden faydalanılmıştır. Çalışmada, öncelikle TOPSIS yöntemine ilişkin bilgiler verilecektir. Daha sonra, Türkiye'de 81 il için bilgi ekonomisi indeksi sıralaması yapılarak mevcut durum üzerine değerlendirmeler yapılacaktır.

\section{Bilgi Ekonomisinin Başlıca Göstergeleri}

Ülkeler açısından iktisadi kalkınma sürecinin temelinde bilginin üretilmesi ve kullanımı yer almaktadır. Bilgiden etkin bir şekilde yararlanan toplumlar bilgi ekonomisi haline gelerek ekonomik kalkınmalarını sağlamaktadır. Kalkınmanın ana motoru olarak da görülen bilgi ekonomisinin belirleyicileri, bir ülkenin 
veya bölgenin bilgi toplumuna yönelik gelişim düzeyini temsil eden ve ekonomik kalkınma için bilginin nasıl daha verimli kullanılacağını yansıtan göstergelerdir (Bashir, 2013, s.31). Bilgi toplumunun ekonomik ve kurumsal anlamda genel çerçevesinin çizilmesinde önemli bir rolü bulunan yenilik, eğitim, bilgi ve iletişim teknolojileri Dünya Bankası tarafından bilgi ekonomisinin yapı taşları olarak görülmektedir (Chen ve Dalhman, 2005, s.4). Bununla birlikte bilginin etkili ve verimli bir şekilde kullanılması açısından uygun ekonomik politikalara sahip olması gerekmektedir.

\section{Ekonomi Politikalarn-Gelir Düzeyi}

İnsanların sahip olduğu gelir düzeyi ekonomik özgürlük derecesini de belirlemektedir. Kişi başına gelir düzeyi yükseldikçe bilgiye olan ulaşımda da artış yaşanmaktadır (Bashir, 2013, s.32). Zaman içerisinde gelişmiş ve gelişmekte olan ülkeler arasında oluşan bilgi düzeyi farklılı̆̆ının gelir düzeyi farkının üzerinde olduğu aktarılmaktadır. Diğer yandan kamu kesiminin uygulayacağı ekonomi politikaları da bilginin oluşturulması, kullanılması ve yayılması bakımından teşvik edici bir rol üstlenmektedir (Chen ve Dahlman, 2005, s.7).

\section{Yenilik Sistemleri}

İktisat teorisine göre verimlilik artışı ve teknik ilerleme açısından yenilik sistemleri anahtar konumda yer almaktadır. Bilginin yenilikler vasıtasıyla işlenmesi ve üretilmesi aşamasında üniversiteler, araştırma enstitüleri, düşünce kuruluşları ve özel işletmelere, küreselleşmeyle artan bilgi birikiminden yararlanma ve yerelin ihtiyaçlarının karşılanması amacıyla büyük görev düşmektedir. Etkin bir yenilik sistemi yeni ürünler, yeni süreçler ve yeni bilgilerle ortaya koyulan ilerlemeyi yansitmaktadır. Bu noktada ise özellikle patent ve ArGe'nin rolü bulunmaktadır. Literatürde yer alan Mansfield (1972), Romer (1990) ve Stokey (1995) gibi çalışmalar özellikle Ar-Ge harcamalarının ekonomik büyümeyi olumlu yönde etkilediğine dair sonuçlar taşımaktadır.

Patent: Bilgi ekonomisinin göstergeleri açısından bilgiye atfedilen en önemli noktalardan birisi de bir ürün ya da yöntemin en kolay şekilde nasıl ticari gelir kaynağı haline dönüştürülebilir olmasıdır. Metalaşan bilginin, ticari bir sır olarak saklanması ve korunması için patentinin alınması gerekmektedir (Oğuz, 2012, s.5). İcat ve yeniliklerin ticarileştirilmesi ile piyasada nihai ürün haline dönüştürülen teknoloji yeteneğinin göstergeleri bakımından patent önemli bir yere sahiptir. Şirketlerin teknolojik yenilik faaliyetlerinde girdi olarak Ar-Ge çalışmaları görülmekte iken, bu çalışmaların sonucunda meydana gelen çıktılar ise patent sayısı olarak ifade edilmektedir (Salur, 2019, s.156). 
Ar-Ge: Ar-Ge kavram itibariyle yenilik, buluş, ürün geliştirme, süreç iyileştirme ile birlikte mevcut işi genişletme, yenileme, ortaya koyma potansiyeline sahip ve bu süreçlerde teknolojiyle ilgili her türlü faaliyeti kapsamaktadır (Yaylalı, Akan, Işık ve 2010, s.14). Bu bağlamda Ar-Ge harcamaları ekonomiler açsindan bilim ve teknolojideki gelişmeleri ana teşvik eden unsur olarak yer almaktadır (Bozkurt, 2015, s.189). Ülke ekonomisinin iç dinamikleriyle oluşturduğu teknoloji alanındaki yenilikler bilgi üretiminin ana kaynağı olarak sayılmaktadır. Bir ülkenin Ar-Ge düzeyi bilgi ekonomisi konusunda ne kadar ilerleme gösterdiğini ortaya koymaktadır (Ünal ve Seçilmiş, 2013). Aynı zamanda Ar-Ge faaliyetlerinin somut çıktısı olarak kabul edilen yenilik; şirketlerin performansı, başarısı ve rekabet gücü açısından büyük öneme sahiptir (Van Auken, Madrid-Guijarro ve Garcia-Perez-De-Lema, 2008, s.51). Gelişmekte olan bir ülkenin yenilik stratejilerinin temel unsuru, büyüyen küresel bilgi tabanından yararlanmanın en iyi yollarını bulmak ve yerel Ar-Ge kapasitesini nerede ve nasıl kullanacağına karar vermektir.

\section{Ĕ̆itim Düzeyi}

Bilgi ekonomisinin en önemli göstergelerinden biri olan eğitim, teknolojiyi ve yeniliği gerek üreten gerekse geliştiren insan gücünün oluşturulmasında önemli bir paya sahiptir (Kaynak, 2008, s. 91). Gelişmiş ekonomiler incelendiğinde emek yoğun işgücü günümüzde giderek yerini bilgi yoğun şekilde çalışan emeğe bırakmaktadır. Toplumlardaki artan istihdamı ihtiyacını karşılayabilmek için bilgi ve teknoloji üretimine yatkın Ar-Ge çalışmalarına yönelik yetenekli insan modeli tercih edilmektedir (Türkiye Bilişim Vakfi [TBV], 1996, s. 10). Yüksek teknolojiye gereksinim duyan savunma sanayi, ilaç sanayi, uzay teknolojisi ile elektrik-elektronik ürünlerin üretildiği yüksek bilgi birikimi gerektiren alanlarda lisans ve lisansüstü eğitimi bulunan nitelikli iş gücüne ihtiyaç duyulmaktadır (Salur, 2019, s.154). Aynı zamanda işletmelerin Ar-Ge faaliyetlerinde çalıştırdıkları araştırmacı sayısı da şirketlerin performansını, verimliliğini ve rekabet gücünü yükseltmede önemli bir etkiye sahiptir (Kaynak, 2011 s.54).

\section{Bilişim Altyapısı}

Bilgi ekonomisi göstergeleri açısından değinilmesi gereken bir diğer unsur ise bilgi ve iletişim teknolojisi kavramıdır. Verilerin belirli işlem sürecinden geçirildikten sonra yeni bilgiler üretilmesi, elektronik ortamda kaydedilmesi, saklanması ve taşınılmasını sağlayan kavramdır. Bilgi ekonomisinin meydana geliş sürecinde bilginin dolaşımı, kullanımı, erişimi ve saklanması için bilgi ve iletişim alt yapısının oluşturulması oldukça önemlidir (Yaylalı vd., 2010, s.10). 
Bu altyapı sadece yüksek teknolojiye sahip internet ve telefon kullanımı değil aynı zamanda bilginin kullanılması, saklanması ve yayılması için kullanılan televizyon, radyo ve sabit telefon gibi telekomünikasyon hizmetlerini de kapsamaktadır (Özkan ve Çelik, 2018, s.4). Günümüzde bilgi ekonomisinin gelişmesiyle birlikte bir mal veya hizmet satın almak, ortak ürün çıkartma, para transferleri, sözleşme ve ihaleler gibi ekonomik faaliyetlerin büyük bir kısmı internet aracilı̆̆ıyla gerçekleşmektedir (Gürdal, 2004, s.54). Bilişim teknolojilerinin yoğun olarak kullanıldığı toplumlarda üretimde artış, işleyişte kolaylık, ekonomik çıktı ve ihracat gelirlerinde yükseliş yaşanmaktadır (Uçkan, 2006, s.30).

\section{Literatür Taraması}

İllerin gelişme stratejilerinin oluşturulmasında öncelikle ekonomik ve sosyal durumlarının tespit edilmesi ve potansiyellerinin ortaya çıarılması gerekmektedir. Türkiye'de bölgeler, iller ve ilçeler arasında sosyal, kültürel ve ekonomik gelişme süreçlerinde farklılıklar görülmektedir. Bu sebeple söz konusu iller ve ilçeler arasında sosyo-ekonomik farklılıklar söz konusu olmuştur (Kılıç, Saraçlı ve Kolukısaoğlu, 2011, s.58). Bölgeler arası gelişmişlik farklılıklarının azaltılması amacıyla oluşturulacak politikaların hazırlanmasında, bölgelerin gelişmişlik düzeylerinin sosyokültürel ve ekonomik değişkenler yardımıyla ölçülmesi önem taşımaktadır (Kart ve Keser, 2019, s.27). Türkiye'deki illerin sosyo-ekonomik gelişmişlik düzeylerini belirlemek amacıyla çeşitli çalışmalar yapılmıştır. Literatür incelendiğinde genellikle çalışmaların illerin ekonomik gelişmişlik düzeylerine odaklandığı görülmektedir. Bu çalışmalardan bazılarına aşağıda yer verilmiştir.

Dinçer vd. (2003), Türkiye'de 81 il için sosyo-ekonomik gelişmişlik seviyelerinin tespit edilmesi amacıyla yaptıkları çalışmada; Dinçer (1996) tarafından yapılan çalışma ile aynı değişkenleri kullanarak iki dönem arasındaki değişimleri ortaya koymuşlardır. Yıllar itibariyle sıralamada üst seviyelere atlayan iller, konumu değişmeyen iller ve sırası gerileyen iller belirtilerek bu durumların olası sebepleri değerlendirilmeye çalışlmıştır.

Şen vd. (2006), Türkiye'deki illerin gelişmişlik düzeylerini belirlemek amacıyla faktör analizi ve temel bileşenler analizi kullanarak yaptıkları çalışmada, il sonuçlarını sıralayarak gelişmişlik sıralamasına ulaşmıştır. Elde edilen sonuçlara göre en gelişmiş il İstanbul iken en az gelişmiş il Bilecik olarak elde edilmiştir. Çalışma sonucunda ilk sıralarda yer alan illerin batıda; son sıralarda yer alan illerin ise Doğu Anadolu ve Güneydoğu Anadolu Bölgesinde bulunduğu belirtilmiştir. 
Gül ve Çevik'in (2015), Türkiye'de illerin gelişmişlik düzeyini ölçmek amacıyla oluşturdukları endeks sonucuna göre ilk üç il İstanbul, Ankara ve İzmir olurken, Bitlis, Muş ve Hakkâri ise endeksin son üç sırada yer almıştır.

Çakın ve Özdemir (2015), Ar-Ge ve inovasyon göstergelerini kullanarak TOPSIS yöntemi ile inovasyon performansını değerlendirdikleri çalışmada, Düzey 1'de yer alan 12 bölgenin performanslarını sıralamışlardır. En yüksek performansa sahip bölgeler sırasıyla İstanbul Bölgesi, Doğu Marmara Bölgesi ve Ege Bölgesi olarak bulunmuştur. En düşük performansa sahip bölgeler ise Kuzeydoğu Anadolu, Ortadoğu Anadolu, Doğu Karadeniz ve Batı Karadeniz bölgeleri olarak bulunmuştur.

Özpınar ve Koyuncu (2016), eğitim, sağlık ve gelir bileşenlerini içeren insani gelişme endeksini il bazında sıraladığı çalışmasında, alt endeks sıralamasına göre eğitimde Eskişehir ve Isparta'nın; sağlıkta Tunceli ve Mardin'in; gelir seviyesinde Yalova ve Kocaeli'nin ilk iki sırada yer aldığını göstermişlerdir. İnsani gelişme endeksi sıralamasında ise ilk üç il Eskişehir, Yalova ve Bolu olarak tespit edilmiştir. Aynı şekilde eğitim, sağlık ve gelir bileşenleri ile illerin insani gelişme endeksi hesaplamayı amaçlayan Güler vd. (2016), yaptıkları analizler sonucunda; eğitimde Eskişehir ve Ankara, sağllkta Tunceli ve Mardin, gelir endeksinde Kocaeli ve İstanbul, genel insani gelişme endeksi hesaplamasında ise ilk iki ili Ankara ve İzmir olarak belirtmişlerdir.

SEGE (2017), İllerin ve Bölgelerin Sosyo-Ekonomik Gelişmişlik Sıralaması2017 Araştırmasında, il ve Düzey-2 bölgelerinin SEGE endeks değerleri ve s1ralamaları elde edilmiştir. Genel endeks değerlerinin yanı sıra eğitim, sağlık, demografi, rekabetçi ve yenilikçi kapasite, istihdam, mali erişilebilirlik ve yaşam kalitesi başlıklarında illerin sıralamaları oluşturulmaya çalışılmıştır. Yapılan analizler sonucunda, rekabetçi ve yenilikçi iller sıralamasında ilk üç sırayı İstanbul, Ankara ve İzmir illeri alırken, Şırnak, Muş ve Ağrı son üç il olarak bulunmuştur.

Dilek ve Al (2016), Ekonomi ve Dış Politika Araştırma Merkezi (EDAM) tarafindan illerin rekabet endeksini sekiz alt endeks ile hesaplanmıştır. Sekiz alt endeksin birleşiminden oluşan bileşik rekabetçilik endeks değerlerinde 2008 ve 2014 yıllarında ilk on il açısından sıralamada anlamlı bir değişiklik olmadığını belirtmişlerdir. İnsan sermayesi endeksinde ilk üç il Ankara, Tunceli ve Eskişehir olurken; yaratıcı sermaye endeksinde Ankara, İstanbul ve Eskişehir ilk üç il olarak bulunmuştur.

URAK (2018), iller arası rekabet endeksi hesaplamalarında, Türkiye'de illerin rekabetçiliğinin yenilenebilir şekilde ölçülmesini amaçlamıştır. Yenilikçilik, 
beşerî sermaye, yaşanabilirlik, üretim ve ticaret alt endekslerinden oluşan çalışmada önceki yıllara ait değerler ile karşılaştırmalı bir değerlendirme yapılmıştır. 2016-2017 yıllarına ait değerlere göre, beşerî sermaye alt endeksinde ilk üç il Ankara, İstanbul ve Kırşehir; yenilikçilik alt endeksinde ilk üç il İstanbul, Ankara ve İzmir; yaşanabilirlik alt endeksine göre ilk üç il ise İstanbul, Ankara ve Trabzon olarak belirtilmiştir.

İstanbul Üniversitesi Şehir Politikaları Uygulama ve Araştırma Merkezi tarafindan hazırlanan İller Arası Rekabet Endeksi'ne (2020) göre; 2018-2019 yılları için, yükseköğretim endeksinde ilk beşil İstanbul, Ankara, Eskişehir, İzmir ve Isparta'dır. Teknolojik altyapı endeksinde ilk beş il İstanbul, Ankara, İzmir, Kocaeli ve Bursa olarak gösterilmiştir. İnovasyon endeksi sıralamasında ilk beş il İstanbul, Ankara, Bursa, Kocaeli ve İzmir'dir, Eğitim endeksinde ise; Denizli, Edirne, Ankara, Nevşehir ve Amasya ilk beş il olarak tespit edilmiştir.

Belgin ve Apaydın Avşar (2019), Türkiye'de illerin Ar-Ge ve yenilik performanslarını ölçmek amacıyla Gri İlişkisel Analiz Yöntemini kullanarak illeri performans puanlarına göre sıralamışlardır. Yapılan analiz sonuçlarına göre ilk üç il sırasıyla İstanbul, Ankara ve İzmir olarak bulunurken, son üç il Iğdır, Bayburt ve Ardahan olarak tespit edilmiştir.

Teknolojinin gelişmesi ile birlikte bilgi toplumu ve bilgi ekonomisi kavramları gündeme gelmiştir. Yukarıda belirtilen çalışmalardan da görüldüğü üzere illerin genellikler ekonomik durumlarının tespitine yönelik çalışmalar çoğunluktadır. Bazı çalışmalarda yenilikçilik alt endeksleri oluşturulsa da illerin bilgi ekonomisi açısından mevcut durumlarını gösteren bir çalışmaya rastlanmamıştır. Bilgi ekonomisi endeksi oluşturulmaya çalışılan bu çalışmada literatür taramasında elde edilen kriterlerin bazıları eklenerek illerin ekonomik ve yenilikçilik durumları dahil edilmeye çalışılmıştır. Bu çalışmada diğerlerinden farklı olarak bilgi ekonomisi değişkenleri kullanılarak Türkiye'deki 81 il için endeks oluşturulacak ve sıralama yapılacaktır.

\section{TOPSIS Yöntemi}

Entropi ağırlık yönteminin uygulama adımları (Çakır ve Perçin, 2013, s.77-95; Li vd., 2011, s.2085-2091; Perçin ve Sönmez, 2017, s.570-571; Wu vd., 2011, s.5162-5165)'de detaylı gösterilmiştir. Buna göre, öncelikle çok kriterli bir karar probleminde $\mathrm{m}$ tane alternatif ve $\mathrm{n}$ tane kriter olduğunda karar matrisi düzenlenmektedir. Standardize işlemleri yapılır ve karar verme problemlerinde kriterler fayda ve maliyet olmak üzere farklı şekillerde standardize edilebilir. Tüm kriterlerin Entropi değerlerinin hesaplanmasının ardından kriterlerin Entropi 
ağırlığı hesaplanmaktadır. Entropi ağırlı̆̆ yararlı bilginin derecesini gösterdiğinden daha büyük Entropi ağırlı̆ğna sahip kriterin karar verme ve değerlendirme açısından daha önemli olduğu sonucuna varılmaktadır.

Karar verme sürecinde yararlanılan yöntemlerden biri olan TOPSIS yöntemi, ilk defa 1981 yılında Hwang ve K. Yoon tarafindan ortaya konmuş ancak 1992 yılında Chen ve Hwang tarafından yöntem geliştirilmiştir. Yöntemin amacı geliştirilen alternatiflerin tercih sıralamasın belirlemek ve seçilen alternatifin optimum sonuca en yakın, negatif optimum sonuca ise en uzak olmasidir (Alpaykut, 2017, s.379; Hwang ve Yoon, 1981; Wang ve Lee, 2009, s.8981). Yöntemin uygulanabilmesi için en az iki alternatifin olması gerekmektedir.

TOPSIS yöntem ile tüm alternatiflerin pozitif ve negatif optimum sonuca olan uzaklıkları hesaplanmaktadır. Pozitif ideal çözüme en yakın ve negatif optimum sonuca ise en uzak mesafede olan seçenek en iyi alternatif olarak kabul edilmektedir (Cheng, Chan ve Huang, 2002, s.983). Bu yöntem karmaşık algoritmalar ve matematiksel modeller içermemesi ve değerlendirme kriterlerinin ağırlıklandırılmasını mümkün kılması gibi üstünlüklerinden ötürü literatürde sıkça yararlanılan yöntemlerdendir (Çakır ve Perçin, 2013, s.79).

Amaçların tespiti ve değerlendirme kriterlerinin belirlenmesinden sonra TOPSIS yönteminin aşamaları aşağıda verilmiştir (Hwang ve Yoon, 1981, s.128; Özbek, 2017, s.72; Yoon and Hwang, 1995, s.39-41).

Adım 1: Karar matrisinin oluşturulması

Karar matrisinde, alternatifler $\left(a_{1} \ldots a_{n}\right)$ altalta sıralanarak karşılarındaki her bir kriterin benzerlerine göre gösterdikleri özellikler aktarılır (Yurdakul ve İç, 2003, s.11-12). Karar matrisi aşağıdaki gibi yer almaktadır:

$$
A_{i j}=\left[\begin{array}{cccc}
a_{11} & a_{12} & \ldots & a_{1 n} \\
a_{21} & a_{22} & \ldots & a_{2 n} \\
\cdot & & & \cdot \\
\cdot & & & \cdot \\
\cdot & & & \cdot \\
a_{m 1} & a_{m 2} & \ldots & a_{m n}
\end{array}\right]
$$

$A_{i j}$ matrisinde m karar noktası sayısını, n değerlendirme faktörü sayısını göstermektedir.

Adım 2: Karar matrisinin normalize edilmesi

Karar matrisindeki kriterlere ilişkin puan veya özelliklerin kareleri toplamının karekökü alınarak matris normalleştirilir (Yurdakul ve İç, 2003, s.11-12). Normalleştirme sürecinde aşağıdaki eşitlikten yararlanılmaktadır. Normalleştirme işlemi neticesinde aşağıdaki eşitlikte yer alan $\mathrm{R}$ matrise ulaşılmaktadır. 


$$
r_{i j}=\frac{a_{i j}}{\sqrt{\sum_{k=1}^{m} a_{k j}^{2}}}
$$

$\mathrm{i}=1,2, \ldots, \mathrm{n} \quad \mathrm{j}=1,2, \ldots, \mathrm{k}$

$$
R_{i j}=\left[\begin{array}{cccc}
r_{11} & r_{12} & \cdots & r_{1 n} \\
r_{21} & r_{22} & \cdots & r_{2 n} \\
- & & - \\
- & & - \\
- & r_{m 2} & \cdots & r_{m n}
\end{array}\right]
$$

Adım 3: Ağırlıklandırılmış normalize edilmiş karar matrisinin oluşturulması Değerlendirme faktörlerine ait ă̆ırlık değerleri $\left(w_{i}\right)$ belirlendikten sonra R matrisinin bütün sütunlarındaki elemanlar, ilgili $w_{i}$ değeri ile çarpılarak $\mathrm{V}$ matrisi şekillendirilir. V matrisi aşağıdaki gibidir:

$$
V_{i j}=\left[\begin{array}{cccc}
w_{1} r_{11} & w_{2} r_{12} & \cdots & w_{n} r_{1 n} \\
w_{1} r_{21} & w_{2} r_{22} & \cdots & w_{n} r_{2 n} \\
- & & & - \\
- & & & - \\
w_{1} r_{m 1} & w_{2} r_{m 2} & \cdots & w_{n} r_{m n}
\end{array}\right]
$$

Adım 4: Pozitif ideal çözüm ve negatif ideal çözümün belirlenmesi

Pozitif ideal çözüm setinin oluşturulabilmesi için V matrisindeki sütun değerlerinin en büyükleri seçilir. Negatif ideal çözüm seti ise, V matrisindeki sütun değerlerinin en küçükleri belirlenerek hazırlanır (Shyjith, llangkumaran ve Kumanan, 2008, s.381). İdeal sonuçlar altta yer alan eşitlikler kullanarak hesaplanabilmektedir.

$$
\begin{aligned}
& A^{*}=\left\{\left(\max _{i} v_{i j} \mid j \in J\right),\left(\min _{i} v_{i j} \mid j \in J^{\prime}\right\}\right. \\
& A^{-}=\left\{\left(\min _{i} v_{i j} \mid j \in J\right),\left(\max _{i} v_{i j} \mid j \in J^{\prime}\right\}\right.
\end{aligned}
$$

Her iki formülde de $j$ maksimizasyon, $J^{\prime}$ ise minimizasyon değerini belirtmektedir (Monjezi, Dehghani, Singh, Sayadi ve Gholinejad, 2010, s.3). 
Adım 5: Ayırım Ölçülerinin Hesaplanması

TOPSIS yönteminde her bir karar noktasına ait değerlendirme faktör değerinin ideal ve negatif ideal çözüm setinden sapmaları bulunur. Elde edilen karar noktalarına ait sapma değerleri ise Pozitif İdeal Ayırım $\left(S_{i}^{*}\right)$ ve Negatif İdeal Ayırım $\left(S_{i}^{-}\right)$ölçüsü şeklinde isimlendirilmektedir.

Her alternatifin pozitif ideal çözüme olan mesafesi aşağıdaki gibi belirlenir:

$S_{i}^{*}=\sqrt{\sum_{j=1}^{n}\left(v_{i j}-v_{j}^{*}\right)^{2}}$

Alternatiflerin negatif ideal çözüme olan mesafelerde de aşağıdaki gibi hesaplanır:

$S_{i}^{-}=\sqrt{\sum_{j=1}^{n}\left(v_{i j}-v_{j}^{-}\right)^{2}}$

Burada hesaplanacak $S_{i}^{*}$ ve $S_{i}^{-}$sayısı karar noktası sayısı kadar olacaktır.

Adım 6: İdeal Çözüme Göreli Yakınlığın Hesaplanması

Tüm karar noktalarının ideal çözüme göreli yakınlı̆ı̆ın $\left(C_{i}^{*}\right)$ hesaplanmasında ideal ve negatif ideal ayırım ölçülerinden faydalanılmaktadır. İdeal çözüme ilişkin yakınlık değerinin hesaplanması aşağıda gösterilmiştir.

$$
C_{i}^{*}=\frac{S_{i}^{-}}{S_{i}^{-}+S_{i}^{*}}
$$

Burada $C_{i}^{*}$ değeri $0 \leq C_{i}^{*} \leq 1$ aralığında değer alır ve $C_{i}^{*}=1$ ilgili karar noktasının ideal çözüme, $C_{i}^{*}=0$ ilgili karar noktasının negatif ideal çözüme mutlak yakınlı̆̆ını göstermektedir.

Adım 7: $C_{i}^{*}$ değerlerinin karşılaştırılması ve alternatiflerin sıralarının belirlenmesi Alternatifler $C_{i}^{*}$ değerlerine göre sıralanırlar. Maksimum $C_{i}^{*}$ değeri seçilir. Böylece Alternatiflerin nihai sıralaması elde edilir.

Literatür incelendiğinde TOPSIS yönteminin kullanıldığı birçok çalışmaya rastlanmıştır. Yurdakul ve İç (2003), Türk otomotiv firmalarının performans ölçümü yaptıkları çalışmada; Eleren ve Karagül (2008), Türkiye ekonomisinin performans değerlendirmesini yaptıkları çalışmada; Dumanoğlu ve Ergül (2010) İMKB'de işlem gören teknoloji şirketlerinin mali performans ölçümünde; Demireli (2010), Türkiye'deki kamu bankaları üzerine bir değerlendirme yaptığı çalışmada; Yayar ve Baykara (2012), katılım bankalarının etkinliği ve verimliliğini inceledikleri çalışmada; Uygurtürk ve Korkmaz (2012), finansal performans incelemesinde; Öztürkoğlu ve Türker (2013), paydaş ilişkilerini inceledikleri çalışmada; Ömürbek ve Kınay (2013), havayolu taşımacilığ sektöründe finansal performans değerlendirmesinde; Karaatlı vd. (2015), yaşanabilir illerin sıralanmasını oluşturdukları çalışmada; Orçun ve Eren (2017), finansal performans değerlendirmesinde; Işık (2019), finansal performans ile pay 
senedi getirileri arasındaki ilişkinin incelenmesinde TOPSIS yönteminin kullanıldığı görülmektedir. Ancak Türkiye illeri için TOPSIS yöntemi kullanılarak bilgi ekonomisi indeksi sıralaması yapan çalışmaya rastlanmamıştır. Çalışmanın bu yönüyle literatüre katkı sağlayacağı düşünülmektedir.

\section{Türkiye'de 81 İl İçin Bilgi Ekonomisi İndeksi Sıralaması}

Ülkelerin ekonomik büyüme ve gelişmelerinde sahip oldukları bilginin niteliği ve niceliğinin önemi büyüktür. Günümüzün iktisadi ve sosyal açıdan gelişmiş toplumları "Bilgi Toplumu", bu toplumların sahip oldukları ekonomik anlayış ise "Bilgi Temelli Ekonomiler" olarak adlandırılmaktadır. Bilgi temelli ekonomiler için; bilginin kullanılması ve yayılmasını teşvik eden ekonomik ve kurumsal model, büyüyen küresel bilgi stokundan beslenebilen yenilik sistemi, bilgiyi yaratabilen ve kullanan eğitimli nüfus, etkili iletişime olanak sağlayan enformasyon altyapısı temel alınmaktadır (Yumuşak ve Bilen, 2010, s.101). Bilgi ekonomisi, beşerî sermaye temelli bir yapıya sahip olması sebebiyle, çalışanların okuryazarlık ve okuryazarlıkla mücadele durumu, kırsal alanda yaşayan kesimin eğitim durumu, yüksekokul veya fakülte mezunu ve işsizlik seviyesi gibi değişkenler etkilemektedir (OECD, 2011, s.115). European Bank (2019) bilgi ekonomi endeksi dört temel sütundan oluşmaktadır. Bunlar; endüstriyel yenilik (ticarete açık ekonomiler, işgücü hareketliliği, yatırım, iş çevresi ve hükümet), yenilik becerileri (eğitim seviyesi, uzmanlaşmış kişi sayısı), yenilik sistemleri (yenilik sistemi içinde girdiler, çıktılar, bağlantılar, patent ve bilimsel yayın sayısı) ve bilgi iletişim teknolojileridir (bilgi iletişim teknoloji altyapısı, geniş bant hızı ve aralığı). Dolayısıyla bilgi ekonomisi indeksi, ülkelerin bilgi altyapısı, ekonomik teşvikler, eğitim-öğretim, kurumsal rejim ve yenilik alanlarındaki performanslarına dayanan bir indekstir. Bir ülkenin bilgi ekonomisi açısından konumu belirlenirken, Ar-Ge faaliyetleri ve Ar-Ge harcamalarının büyüklüğü ile finansmanı, bilimsel yayın sayısı, patent başvuru sayıları, bilim ve teknoloji açısından insan kaynağı büyüklüğü, bilgi elde etmeye yönelik yatrrımlar (üniversiteler ve Ar-Ge harcamalarına yönelik yatırımlar) ile bilgi iletişim teknolojileri sektöründeki gelişmeler etkili olmaktadır (Sayar Özkan ve Alancioğlu, 2017, s.5-6).

Türkiye'deki illeri bilgi ekonomisi indeksine göre sıralamak amacıyla yapılan bu çalışmada karar seçenekleri olarak kullanılacak değişkenler Tablo 1'de gösterilmiştir. 
Tablo 1. Kullanılan değişkenler

\begin{tabular}{l}
\hline Geniş Bant İnternet Abone Sayısı \\
\hline Patent başvuru sayısı \\
\hline Akademisyen sayısı \\
\hline Okuryazarlı durumuna göre nüfus \\
\hline Yüksekokul veya fakülte mezunu \\
\hline Lisansüstü mezunu \\
\hline Kişi başı̇na GSYH(TL) \\
\hline
\end{tabular}

Bu çalışmada ölçütlerin ağırlıklarını belirlemek amacıyla Entropi Ağırlık tekniği kullanılmıştır. Entropi Ağırlık tekniğinden nitel ve nicel faktörleri birlikte değerlendirmesinden ötürü yararlanılmaktadır. Entropi Ağırlık tekniği, kriterlerin önem düzeylerinin belirlenmesinde kullanılmaktadır. Entropi Ağırlık tekniği, karar vericilerin sübjektif kararlarına dayanarak ağırlıkların hesaplandığı Delphi ve AHP gibi yöntemlerden ayrı olarak, mevcut verilerden yararlanarak hesaplama yapan objektif bir ağırlık belirleme yöntemidir (Çakır ve Perçin, 2013, s. 79). Değişkenler ait Entropi ağırlıkları Tablo 2'deki gibidir.

Tablo 2. Değişkenlerin Entropi ile Belirlenen Ağırlıkları

\begin{tabular}{ll}
\hline Değişkenler & Ağırlık \\
\hline Geniş Bant İnternet Abone Sayısı & 0.027094925 \\
\hline Patent başvuru sayısı & 0.560490565 \\
\hline Akademisyen sayısı & 0.152351826 \\
\hline Okuryazarlık durumuna göre nüfus & 0.020241522 \\
\hline Yüksekokul veya fakülte mezunu & 0.065169109 \\
\hline Lisansüstü mezunu & 0.106859502 \\
\hline Kişi başina GSYH(TL) & 0.067792552 \\
\hline
\end{tabular}

Tablo 3'de TOPSIS yöntemi ile hesaplanan $C_{i}^{*}$ ideal çözüme yakınlık değerlerine göre illerin bilgi ekonomisi performans sıralaması gösterilmiştir.

Tablo 3. İlerin bilgi ekonomisi indeksi sıralamaları

\begin{tabular}{llllll}
\hline İL & SIRA & İNDEKS $\left(\boldsymbol{C}_{\boldsymbol{i}}^{*}\right)$ & İL & SIRA & İNDEKS $\left(\boldsymbol{C}_{\boldsymbol{i}}^{*}\right)$ \\
\hline İstanbul & 1 & 0.91003054 & Uşak & 42 & 0.134245184 \\
\hline Ankara & 2 & 0.759885252 & Zonguldak & 43 & 0.133881673 \\
\hline Manisa & 3 & 0.712476685 & Bolu & 44 & 0.129135442 \\
\hline Kocaeli & 4 & 0.677103873 & Malatya & 45 & 0.129082073 \\
\hline Bursa & 5 & 0.642187872 & Bayburt & 46 & 0.12800268 \\
\hline Sakarya & 6 & 0.624477333 & Burdur & 47 & 0.122188428 \\
\hline Eskişehir & 7 & 0.484373697 & Amasya & 48 & 0.120160742 \\
\hline Tekirdağ & 8 & 0.397793522 & Muğla & 49 & 0.119688914 \\
\hline Konya & 9 & 0.379859033 & Siirt & 50 & 0.119473453 \\
\hline Gaziantep & 10 & 0.311051912 & Sinop & 51 & 0.11777998 \\
\hline İzmir & 11 & 0.309488723 & Sivas & 52 & 0.115016743 \\
\hline Kayseri & 12 & 0.30323339 & Nevşehir & 53 & 0.114488204 \\
\hline Bilecik & 13 & 0.267166931 & Kurşehir & 54 & 0.110281434 \\
\hline Isparta & 14 & 0.256957117 & Niğde & 55 & 0.109220706 \\
\hline Artvin & 15 & 0.243483128 & Erzincan & 56 & 0.104875777 \\
\hline
\end{tabular}


Türkiye'de 81 İl İçin Bilgi Ekonomisi İndeksi Stralamasının Oluşturulması: Çok Değişkenli Karar Verme Yöntemlerinden TOPSIS ile Bir Uygulama

\begin{tabular}{llllll}
\hline Düzce & 16 & 0.23088163 & Kırklareli & 57 & 0.102740926 \\
\hline Denizli & 17 & 0.225017723 & Kilis & 58 & 0.100534699 \\
\hline Erzurum & 18 & 0.224020578 & Şanlıurfa & 59 & 0.100197124 \\
\hline Mersin & 19 & 0.22024607 & Ĭgır & 60 & 0.099107478 \\
\hline Kırıkale & 20 & 0.196189099 & Giresun & 61 & 0.097857526 \\
\hline Tunceli & 21 & 0.195843711 & Karaman & 62 & 0.097370814 \\
\hline Bartın & 22 & 0.191558507 & Şırnak & 63 & 0.08962561 \\
\hline Antalya & 23 & 0.189708726 & Kars & 64 & 0.087374108 \\
\hline Trabzon & 24 & 0.18056371 & Tokat & 65 & 0.077721831 \\
\hline Kütahya & 25 & 0.179006391 & Ardahan & 66 & 0.077292539 \\
\hline Rize & 26 & 0.173695678 & Osmaniye & 67 & 0.076801777 \\
\hline Samsun & 27 & 0.172906039 & Çankırı & 68 & 0.075778708 \\
\hline Aksaray & 28 & 0.169792535 & Ordu & 69 & 0.068796927 \\
\hline Yalova & 29 & 0.16871392 & Hatay & 70 & 0.066510524 \\
\hline Adana & 30 & 0.16409208 & Yozgat & 71 & 0.066087014 \\
\hline Karabük & 31 & 0.163520774 & Van & 72 & 0.059844885 \\
\hline Elâzı̆ & 32 & 0.160873627 & Bingöl & 73 & 0.055742961 \\
\hline Çanakkale & 33 & 0.155124225 & Adıyaman & 74 & 0.054997803 \\
\hline Balıkesir & 34 & 0.150416276 & Diyarbakır & 75 & 0.049559561 \\
\hline Kastamonu & 35 & 0.150387184 & Bitlis & 76 & 0.049370906 \\
\hline Edirne & 36 & 0.149960832 & Batman & 77 & 0.037020038 \\
\hline Gümüşhane & 37 & 0.14567069 & Muş & 78 & 0.032625907 \\
\hline Aydın & 38 & 0.142107312 & Hakkâri & 79 & 0.030136478 \\
\hline Kahramanmaraş & 39 & 0.141113676 & Mardin & 80 & 0.026969836 \\
\hline Çorum & 40 & 0.139321162 & Ağrı & 81 & 0.0214991 \\
\hline Afyonkarahisar & 41 & 0.139298826 & & & \\
\hline & & & & & \\
\hline
\end{tabular}

Tablo 3'de görüldügü̈ üzere, $C_{i}^{*}$ değerleri sıralandığında Türkiye'de bilgi ekonomisi performansı en yüksek olan iller sırasıyla İstanbul, Ankara ve Manisa olarak bulunurken, bilgi ekonomisi performansında geride kalan son üç il sırasıyla Hakkâri, Mardin ve Ağrı olarak tespit edilmiştir.

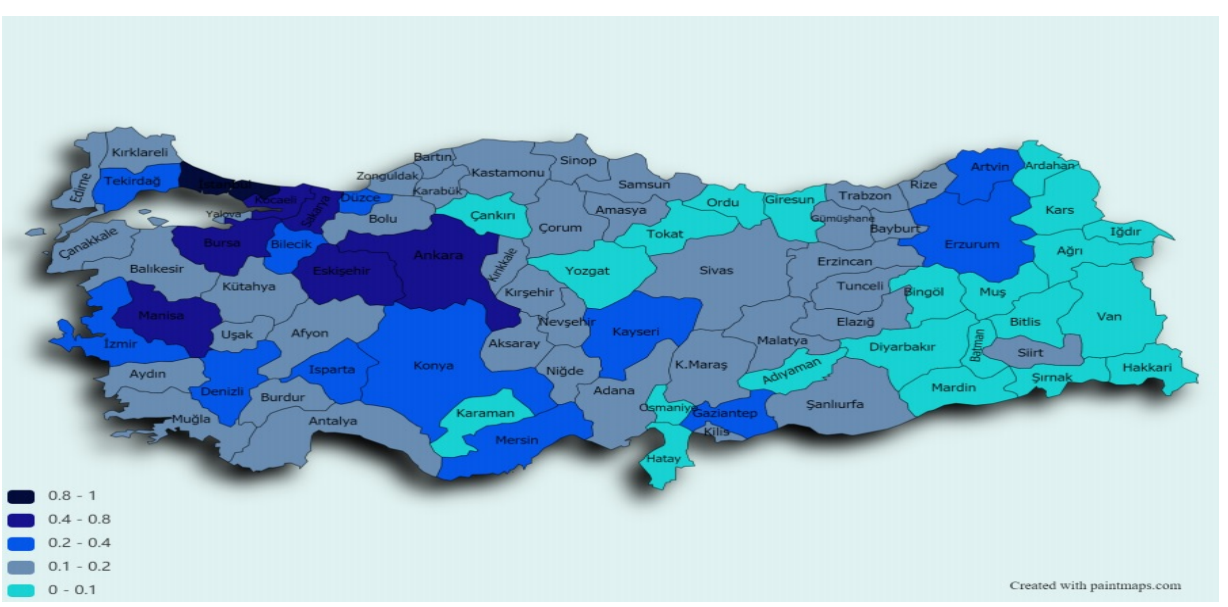

Şekil 1. İllere Ait Bilgi Ekonomisi Sıralamasının Haritalandırılması 
Şekil 1' de Türkiye'de illerin bilgi ekonomisi sıralamasının görselleştirilmesi yer almaktadır. İllerin aldığı değerlere bakıldığında $0-1$ arasında olduğu görülmektedir. İndeks değerinin 0 'dan 1'e doğru yükselmesi neticesinde kentin indeks konumu da yükselmektedir. Haritada illerin değerleri yükseldikçe renkleri koyulaşmakta, sıralamadaki değerleri düşünce ise renkleri açılmaktadır. Harita incelendiğinde çoğunlukla Ankara'nın batısında kalan illerin bilgi ekonomisi indeksi sıralamasında daha üst sıralarda yer aldığı gözükmektedir. Doğu Anadolu Bölgesinde yer alan 14 ilden Erzurum haricindeki iller indeks değeri olarak 0 - 0.2 arasındadır. Güney Doğu Anadolu Bölgesi illeri arasında da Gaziantep haricindekiler $0-0.2$ değerlerini taşımaktadır. Tablo 3'de de yer aldığı üzere sıralamanın en altında yer alan 10 ilden 5'i Güney Doğu Anadolu Bölgesi, 5'i de Doğu Anadolu Bölgesi illeridir. Siralamanın en üstünde yer alan 10 ilden ise 5'i Marmara Bölgesinde bulunmaktadır. Şekil 1'de Marmara Bölgesi illerinin renkleri de bu durumu yansitmaktadır.

\section{Sonuç ve Öneriler}

Günümüz dünyasında kentler; ülkeler, firmalar ve vatandaşlar açısından büyük önem taşımaktadır. Özellikle küreselleşmenin etkisiyle 1980'lerden itibaren üretim süreçlerinde görülen değişmeler, yerelin önemini artırırken kentler de bu durumdan nasiplenmiştir. Aynı süreç bilgi kavramının da giderek gündemde daha fazla yer etmesine yol açmıştır. Bilgi, bir şehir içinde bilgi yoğun faaliyetleri ve ağları teşvik etme, geliştirme ve muhafaza etme olarak ifade edilebilir. Bilgi ekonomisinde meydana gelen gelişmeler neticesinde kentlerin gelişmişlik düzeyleri de değişmektedir. Bu bağlamda il sıralamaları, aynı ülke s1nurları içerisinde bulunan şehirlerin performansını da ölçmeye çalışmaktadır.

Bu eksende çalışmada ekonomik koşulların temelini oluşturan bilgi ekonomisinin Türkiye'de 81 il için sıralamasının yapılması amacıyla indeks oluşturulmaya çalışılmıştır. Bu bağlamda ilk olarak literatürde yer alan çalışmalar incelenerek, bilgi ekonomisi kriterleri için uygun değişkenler belirlenmiştir. Kriterlerin ağırlıkları, mevcut verileri kullanarak hesaplama yapan objektif bir ağırlık belirleme metodu olması sebebiyle entropi yöntemi ile hesaplanmıştır. Devamında bu kriter ağırlıkları kullanılarak TOPSIS yöntemi ile illerin bilgi indeksleri sıralanmıştır. TOPSIS yöntemi ile elde edilen sıralamaya göre bilgi ekonomisi indeksi bakımından ilk üç il İstanbul, Ankara ve Manisa olarak belirlenmiştir. Son üç il ise Hakkâri, Mardin ve Ağrı olarak tespit edilmiştir. Sıralamanın geneli incelendiğinde bilgi ekonomisi indeksi değerlerinin coğrafi olarak farklılaştığı görülmektedir. Bu durum indeks sonuçlarında bölgesel yoğun- 
laşmaların olduğunu göstermektedir. İstanbul ve Ankara'nın ilk sırada yer almasının sebebinin birçok firmanın ana faaliyet merkezlerinin bu illerde olması sebebiyle patent başvurularındaki artsşın görülmesi ve bu illerde bulunan yüksek öğretim kurumu sayısının daha fazla olması nedeniyle bu iki ilin bilgi ekonomisi indekslerinin daha ön sıralarda olduğu düşünülebilir. Ancak sıralamaya bakıldığında büyükşsehirler arasında olan birçok ilin daha alt sıralarda yer aldığı görülmektedir. Elde edilen bulgulara göre, ağırlıklandırma yönteminde patent başvurularının ağıllı̆ı diğer değişkenlere göre daha yüksek bulunmuştur. Bu durum illerin bilgi indeksi sıralamasında daha üst sıralara taşınması için; Ar-Ge faaliyetlerine ve patentli ürün sayılarının arttırılmasına yönelik teşviklerde bulunmaya önem vermeleri gerektiği düşünülmektedir. Akademisyen sayıları ve lisansüstü öğrenci sayıları da illerin bilgi ekonomisi indeksini etkilemektedir. Tablo 3' te verilen listede illerin üst basamaklar ilerlemek için bu değişkenlere önem vermesi gerektiği düşünülmektedir. Türkiye'de bu yöntem ile iller için bilgi ekonomisi sıralaması yapan önceki çalışmalara rastlanmadığından bulgular üzerinde karşılaştırma yapılamamaktadır. Çalışmanın bu yönüyle sonraki çalışmalara yol gösterici nitelikte olacağı düşünülmektedir.

Nihai olarak, Türkiye'deki illere yönelik gerçekleştirilen bilgi ekonomisi indeksi; politikacılar, şehir ve bölge yöneticileri, işletmeler ve gazetecilerin durum tespiti yapabilmeleri adına önemli bir araç olarak görülebilir. İl sıralamaları, küreselleşme ve kentleşmenin kentsel alanlar üzerine olan etkisinin politikacılar ve işletmeler açısından anlaşılabilmesi bakımından da dikkat çekmektedir. Diğer yandan kent ekonomilerinin gelişebilmek için, bilgi yoğun sürece entegre olmaya çok daha fazla ihtiyaçları bulunmaktadır. Bu noktada da özel sektör ve üniversiteler gibi paydaşlara önemli görevler düşmektedir. 


\title{
Extended Abstract
}

\section{Creating Knowledge Economy Index Ranking for 81 Provinces in Turkey: An Application with TOPSIS, One of the Multivariate Decision Making Methods}

*

\author{
Süha Çelikkaya \\ ORCID: 0000-0002-4104-1680 \\ Vahap Karaçadır \\ ORCID: 0000-0002-0089-2112 \\ Zeynep Ezanoğlu \\ ORCID: 0000-0002-4601-7567
}

Since the 1980s, with the development of technology and globalization, the production structure has become more and more efficient and reflects on economic activities. As the importance of human capital increases day by day, technological ability, which is called the ability to produce and use information, has become one of the important determinants of economic growth and international competition. The system based on economic values created by the production, use, dissemination, and interaction of information on global networks is called information economy. The knowledge economy, which forms the basic axis of today's economic conditions, becomes widespread all over the world with the use of technology and becomes a tool of economic, social and cultural development. In terms of countries, the production and use of knowledge is the basis of the economic development process. Societies that make effective use of information ensure their economic development by becoming an information economy. When we look at the basic characteristics of the information economy, information is important and low-cost, communication technologies improve and innovation follow-up is easier thanks to the Internet, emphasis on human capital in the institutional context, and security problems are identified depending on economic, political and cultural issues. Innovation, education, information and communication technologies, which have an important role in drawing the general framework of the information society in economic and institutional terms, are accepted as the building blocks of the knowledge economy by the World Bank. For knowledge-based economies; The economic and institutional model that encourages the use and dissemination of knowledge, 
the innovation system that can feed from the growing global information stock, the educated population that can create and use information, and the information infrastructure that enables effective communication are taken as the basis.

In building the development strategies of the provinces, first of all, it is necessary to determine their economic and social situations and to reveal their potential. As a result of the developments in the knowledge economy, the development levels of the cities also change. In this context, it is tried to measure the performances of the cities within the same country borders with the provincial rankings. Differences in the social, cultural and economic development processes across the regions, provinces and districts of Turkey are observed. Several studies have been conducted to determine their level of socio-economic development of provinces in Turkey. When the literature is examined, it is seen that the studies generally focus on the economic development levels of the provinces. Although innovativeness sub-indices are created in some studies, no study showing the current situation of the provinces in terms of knowledge economy has been found. Unlike others in this study, the index for the 81 provinces in Turkey will be created using different variables as the knowledge economy and ranking will be done.

This study, prepared in order to rank the provinces in Turkey in the knowledge economy index is based on "Knowledge Economy Index" criteria developed by the World Bank. For this purpose, Technique for Order Preference by Similarity to Ideal Solution (TOPSIS) method was used. Entropy Weighting method was used to determine the weights of the variables required for the TOPSIS method. When the literature is examined, many studies using the TOPSIS method have been found. However, Turkey did not find studies that rank the knowledge economy index using TOPSIS method for the provinces. This aspect of the study is thought to contribute to the literature.

As the decision options in this study; The variables of number of broadband internet subscribers, number of patent applications, number of academicians, population according to literacy status, college or faculty graduates, postgraduate graduates, GDP per capita were used. According to the analysis results; Provinces with the highest performance in the knowledge economy in Turkey were found respectively, as İstanbul, Ankara and Manisa, knowledge economy performance in the last three remaining provinces have been identified as Hakkari, Mardin and Agrı. When the overall ranking is examined, it is seen that the values of the knowledge economy index differ geographically. This situation shows that there are regional concentrations in the index results. It can be thought that the reason why Istanbul and Ankara are in the first place is the 
increase in patent applications due to the fact that many companies' main centers of activity are in these provinces and the number of higher education institutions in these provinces can be considered to be at the top of the information economy indexes of these two provinces. According to the findings, the weight of patent applications in weighting method was found to be higher than other variables. In order to move the provinces higher in the information index ranking; It is thought that they should give importance to R\&D activities and incentives to increase the number of patented products. The number of academicians and the number of postgraduate students also affect the knowledge economy index of the provinces.

Since the studies are not found in this method ranking the provinces of Turkey, comparison cannot be made on findings from previous studies. This aspect of the study is thought to be a guide for future studies. As a result, the knowledge economy index for the provinces of Turkey is seen as an important tool for politicians, city and regional administrators, businesses and journalists to conduct due diligence. The city rankings also draw attention in terms of understanding the effect of globalization and urbanization on urban areas in terms of politicians and businesses.

\section{Kaynakça/References}

Alpaykut, S. (2017). Türkiye'de illerin yaşam memnuniyetinin temel bileşkenler analizi ve topsss yöntemiyle ölçümü üzerine bir inceleme. Journal of Suleyman Demirel University Institute of Social Sciences, 29(4), 367-395.

Ataklı Yavuz, R. (2017). Bilgi ekonomisinde kentlerin yeri. Yönetim Bilimleri Dergisi, 15(29), 265-282.

Bashir, M. (2013). Knowledge Economy Index (KEI) 2012 rankings for Islamic Countries and Assessment of ke1 indicators for Pakistan. International Journal of Academic Research in Economics and Management Sciences, 2(6), 1-43.

Belgin, Ö. ve Avşar, B. A. (2019). Türkiye'de bölgeler ve iller düzeyinde ar-ge ve yenilik performansınn gri ilişkisel analiz yöntemi ile ölçülmesi. Verimlilik Dergisi, 2, 27-48.

Bozkurt, C. (2015). R\&D Expenditures and economic growth relationship in Turkey. International Journal of Economics and Financial Issues, 5(1), 188-198.

Chen, D. H. C. ve Dahlman, C. J. (2005). The knowledge economy, the kam methodology and world bank operations. Washington DC: The World Bank, 9-33.

Cheng, S., Chan, C. W. ve Huang, G. H. (2002). Using multiple criteria decision analysis for supporting decisions of solid waste management. Journal of Environment Science Health, 37(6), 975-990.

Coppel, J. (2000). E-Commerce:Impacts and policy challenges. OECD Economic Department Workinkg Papers, No:252, ECO/WKP, 2000/25. 
Çakın, E. ve Özdemir, A. (2015). Bölgesel gelişmişlikte ar-ge ve inovasyonun rolü: DEMATEL tabanlı analitik ağ süreci (danp) ve topsıs yöntemleri ile bölgelerarası bir analiz. Dokuz Eylül Üniversitesi İktisadi İdari Bilimler Fakültesi Dergisi, 30(1), 115-144.

Çakır, S. ve Perçin, S. (2013). AB ülkeleri'nde bütünleşik entropi ağırlık-topsıs yöntemiyle ar-ge performansının ölçülmesi. Uludă̆ Üniversitesi İktisadi ve İdari Bilimler Fakültesi Dergisi, 32(1), 77-95.

Demireli, E. (2010). TOPSIS çok kriterli karar verme sistemi: Türkiye'deki kamu bankaları üzerine bir uygulama. Girişimcilik ve Kalkınma Dergisi, 5(1), 101-112.

Dilek, P. Y. ve Al, N. (2016). Türkiye için bir rekabet endeksi. İmak Ofset Basım Yayın Tic. ve San. Ltd. Şti, İstanbul.

Dinçer, B. (1996). İlerin Sosyo-Ekonomik Gelişmişlik Stralaması. DPT.

Dinçer, B., Özaslan, M. ve Kavasoğlu, T. (2003). İllerin ve bölgelerin gelişmişlik sıralaması araşturmast. DPT, Yayın No:2671, Ankara.

Dulupçu, M. A. (2001). Küresel rekabet gücü. Ankara: Nobel Yayın Dağıtım.

Dumanoğlu, S. ve Ergül, N. (2010). İMKB'de işlem gören teknoloji şirketlerinin mali performans ölçümü. Muhasebe ve Finansman Dergisi, 48, 101-111.

Ekizceleroglu, C. (2011). Türkiye'de bilgi ekonomisi ve bilgi yoğun malların diş ticareti (1969-2009). Marmara Üniversitesi İ.I.B.F. Dergisi, 30(1), 209-228.

Eleren, A. ve Karagül, M. (2008). 1986-2006 Türkiye ekonomisinin performans değerlendirmesi. Celal Bayar Üniversitesi İİ.B.F. Yönetim ve Ekonomi Dergisi, 15(1), 1-14.

Emiroğlu, B. G. (2007). Türkiye ve Dünya'da bilgi toplumu ve ekonomisi: Süreçler ve değişimler. XII. "Türkiye'de Internet" Konferansı, 333-337.

Europan Bank. (2019). Introducing the EBRD knowledge economy index. European Bank for Reconstruction and Development. İngiltere.

Gül, E. ve Çevik, B. (2015). 2013 verileriyle Türkiye'de illerin gelişmişlik düzeyi araştırması. İktisadi Araştırma Raporu. https://ekonomi.isbank.com.tr/ContentManagement/Documents/ar_07_2015.pdf.

Güler, F. E., Çağlar, A., Kangallı Uyar, S. G., Karadeniz, O. ve Yeşilyurt, M. E. (2016). Türkiye'de illere göre insani gelişme endeksi. Sosyal Politikalar Uygulama ve Araştırma Merkezi, Platform Notu:16/P-6.

Gürdal, O. (2004). Bilgi ekonomisi ve/veya yeni ekonomi'nin reddettikleri. Bilgi Dünyası, $5(1), 48-73$

Hwang, C. L. ve Yoon, K. S. (1981). Multiple attribute decision making: Methods and applications. Berlin: Springer-Verlag.

Işık, Ö. (2019). Entropi ve TOPSIS Yöntemleriyle Finansal Performans ile Pay Senedi Getirileri Arasındaki İişkinin İncelenmesi. Kent Akademisi, 12(1), 200-213.

İstanbul Üniversitesi Şehir Politikaları Uygulama ve Araştırma Merkezi. (2020). http://cdn.istanbul.edu.tr/FileHandler2.ashx?f=iller-arasi-rekabet-endeksi-2018-2019raporu-aciklandi.pdf.

Karaatlı, M., Ömürbek, N., Budak, İ. ve Dağ, O. (2015). Çok kriterli karar verme yöntemleri ile yaşanabilir illerin sıralanması. Selçuk Üniversitesi Sosyal Bilimler Enstitüsü Dergisi, 33, 215-228. 
Kart, R. B. ve Keser, İ. K. (2019). Türkiye'deki illerin sosyo-ekonomik gelişmişlik düzeylerinin belirlenmesi ve yerel seçim oy dağılımlarının karşılaştırılması. Türkiye Sosyal Araştırmalar Dergisi, 23(1), 25-52.

Kaynak, S. (2011). Avrupa Birliği yolunda bilim ve teknoloji bağlamında Türkiye'nin AB27 ülkeleri karşısındaki mevcut durumu. Bilgi Ekonomisi ve Yönetimi Dergisi, 6(2), 151159.

Kevük, S. (2006). Bilgi ekonomisi. Journal of Yasar University, 1(4), 319-350.

Kılıç, İ., Saraçlı, S. ve Kolukısaoğlu, S. (2011). Sosyo-ekonomik Göstergeler Bakımından İlerin Bölgesel Bazda Benzerliklerinin Çok Değişkenli Analizler ile İncelenmesi. İstatistikçiler Dergisi: İstatistik ve Aktüerya, 4(2), 57-68.

Li, X., Wang, K., Liu, Xin, J.,Yang, H. ve Gao, C. (2011). Application of the entropy weight and topsis method in safety evaluation of coal mines. Procedia Engineering, 26, 2085 2091.

Mansfield, E. (1972). Contribution of R\&D to Economic Growth in The United States. Science, 175(4021), 477-486.

Monjezi, M., Dehghani, H., Singh, T. N., Sayadi, A. R. ve Gholinejad, A. (2010). Application of TOPSIS Method for Selecting the Most Appropriate Blast Design. Arabian Journal of Geosciences, 5(1), 95-101.

OECD. (2011). Competencies for the knowledge economy. Chapter 4. France: Paris.

Oğuz, S. (2012). Bilgi ekonomisi ve kapitalizm: Eleştirel bir yaklaşım. XVII. Türkiye'de İnternet Konferansi, 79.

Oktay, E. ve Kaynak, S. (2007). Türkiye ve Avrupa Birliği ülkelerinin bilgi ekonomisi girdi ve çıtı değişkenleri arasındaki kanonik ilişkinin araştırılması. Atatürk Üniversitesi Sosyal Bilimler Enstitüsü Dergisi, 10(2), 419-440.

Orçun, Ç. ve Eren, B. S. (2017). TOPSIS Yöntemi ile Finansal Performans Değerlendirmesi: XUTEK Üzerinde Bir Uygulama. Journal of Accounting and Finance, 75, 139-154.

Ömürbek, V. ve Kınay, B. (2013). Havayolu taşımacılığı sektöründe topsıs yöntemiyle finansal performans değerlendirmesi. Süleyman Demirel Üniversitesi İktisadive İdari Bilimler Fakültesi Dergisi, 18(3), 343-363.

Özbek, A. (2017). Türkiye Diyanet Vakfi'nin saw, copras ve topsıs yöntemi ile performans değerlendirmesi. Yönetim ve Ekonomi Araştırmalan Dergisi, 15(1), 66-84.

Özkan, G. S. ve Çelik, H. (2018). Bilgi iletişim teknolojileri ile ekonomik büyüme arasındaki ilişki: Türkiye için bir uygulama. Uluslararası Ticaret ve Ekonomi Araştırmaları Dergisi, 2(1), 1-15.

Özmen, İ. (1998). İlçelerin sosyo ekonomik gelişmişlik sıralaması ve gruplandırılmasına ilişkin bir çalışma. Hazine Dergisi, 11, 41-58.

Özpınar, E. ve Koyuncu, E. (2016). Türkiye'de insani gelişmişlik iller arasında nasıl farklllaşıyor? 81 il için insani gelişmişlik endeksi. Türkiye Ekonomi Politikalanı Araştırma Vakfı (TEPAV) N, 201625.

Öztürkoğlu, Y. ve Türker, D. (2013). Application of TOPSIS to analyze stokeholder relations. International Journal of Business and Social Research, 3(5), 245-255. 
Perçin, S. ve Sönmez, Ö. (2018). Bütünleşik entropi ağırlık ve topsıs yöntemleri kullanılarak Türk sigorta şirketlerinin performansının ölçülmesi. Uluslararası İktisadi ve İdari İncelemeler Dergisi, 565-582.

Romer, P. M. (1990). Endogenous Technological Change. Journal of political Economy, 98(5), II, 71-102.

Salur, S. (2019). Bilgi ekonomisi göstergeleri bakımından Türkiye'nin Avrupa ve Orta Asya ülkeleri arasındaki yeri. Anadolu Üniversitesi Sosyal Bilimler Dergisi, 19(3), 137-166.

Sayar Özkan, G. ve Alancioğlu, E. (2017). Bilgi ekonomisi indeksi performans göstergelerinin Türkiye açısından ar-ge harcamaları analizi. Assam Uluslararası Hakemli Dergi, 4(8), 1-12.

Saygil, Ş. (2003). Bilgi ekonomisine geçiş sürecinde Türkiye ekonomisinin dünyadaki konumu. Ekonomik Modeller ve Stratejik Araştırmalar Genel Müdürlüğü, Stratejik Araştırmalar Dairesi Başkanlığı, Yayın No. DPT, 2675.

SEGE. (2017). https://www.bebka.org.tr/admin/datas/sayfas/89/sege2017_1581687211.pdf.

Shyjith, K., Ilangkumaran, M. ve Kumanan, S. (2008). Multi-criteria decision-making approach to evaluate optimum maintenance strategy in textile industry. Journal of Quality in Maintenance Engineering, 14(4), 375-386.

Stokey, N. L. (1995). R\&D and Economic Growth. The Review of Economic Studies, 62(3), 469489.

Şen, H., Çemrek, F. ve Özaydın, Ö. (2006). Türkiye'de illerin sosyo-ekonomik gelişmişlik düzeylerinin belirlenmesi. SÜ İ̈BF Sosyal ve Ekonomik Araştırmalar Dergisi, 11, 155-171.

Tbv. (1996). Türkiye Bilişim Stratejileri Çalışma Raporu, İstanbul.

Türkiye Sanayicileri ve İş Adamları Derneği. (2001). Avrupa Birliği yolunda bilgi toplumu ve e-Türkiye, İstanbul: TÜSİAD.

Uçkan, Ö. (2006). Bilgi politikası ve bilgi ekonomisi: Verimlilik, istihdam, büyüme ve kalkınma. Bilgi Dünyası, 7(1), 23-48.

Urak (2018). http://www.urak.org/wp-content/uploads/2019/05/URAK_\%C4\%B0RE_2018-2.pdf.

Uygurtürk, H. ve Korkmaz, T. (2012). Finansal performansın topsıs çok kriterli karar verme yöntemi ile belirlenmesi: Ana metal sanayi işletmeleri üzerine bir uygulama. Eskişehir Osmangazi Üniversitesi İktisadi ve İdari Bilimler Fakültesi Dergisi, 7(2), 95-115.

Ünal, T. ve Seçilmiş, N. (2013). Ar-ge göstergeleri açısından Türkiye ve gelişmiş ülkelerle kıyaslama. Işletme ve İktisat Çalışma Dergisi, 1(1), 12-25

Van Auken, H., Madrid-Guijarro, A. ve Garcia-Perez-De-Lema D. (2008). Innovation and performance in Spanish Manufacturing SMEs. International Journal of Entrepreneurship and Innovation Management, 8(1), 36-56.

Wang, T. C. ve Lee, H. D. (2009). Developing a fuzzy topsis approach based on subjective weights and objective weights. Expert Systems with Applications, 36(5), 8980-8985.

Wu, Z., Sun, J., Liang, L. ve Zha, Y. (2011). Determination of weights for ultimate cross efficiency using shannon entropy, Expert Systems With Applications, 38(5), 5162-5165. 
Yayar, R. ve Baykara, H. V. (2012). TOPSIS Yöntemi ile Katılım Bankalarının Etkinliği ve Verimliliği Üzerine Bir Uygulama. Business and Economics Resaerch Journal, 3(4), 21-42.

Yaylalı, M., Akan, Y. ve Işık. C., (2010). Türkiye'de Ar\&Ge Yatırım Harcamaları ve Ekonomik Büyüme Arasındaki EşBütünleşme ve Nedensellik Iliş̧kisi: 1990-2009. Bilgi Ekonomisi ve Yönetimi Dergisi, 5(2), 13-26.

Yeloğlu, H. O. (2009). Bilgi ekonomisi değişkenlerine yönelik ilk izlenimler: TürkiyeOECD Ülkeleri Karşılaştırmaları (1995-1999). Bilgi Dünyası, 10(2), 245-260.

Yoon, K. P. ve Hwang, C. L. (1995). Multiple Attribute Decision Making: An Introduction (104). Sage Publications.

Yumuşak, İ. G. ve Bilen, M. (2010). Türkiye küresel ağa hazır mı? Bilgi ekonomisi indeksi, beşerî kalkınma indeksi ve ağa hazırlık indeksi göstergeleri üzerine bir değerlendirme. Bilgi Ekonomisi ve Yönetimi Dergisi, 5(2), 101-111.

Yurdakul, M. ve İç, Y. T. (2003). Türk otomotiv firmalarının performans ölçümü ve analizine yönelik topsıs yöntemini kullanan bir örnek çalışma. Gazi Üniversitesi Mühendislik ve Mimarlkk Fakültesi Dergisi, 18(1), 1-18 